\title{
Effects of dietary polyunsaturated fatty acids on ovarian and uterine function in lactating dairy cows
}

\author{
R. S. Robinson, P. G. A. Pushpakumara, Z. Cheng, A. R. Peters, \\ D. R. E. Abayasekara and D. C. Wathes* \\ Reproduction and Development Group, Royal Veterinary College, Hawkshead Lane, \\ North Mymms, Hatfield AL9 7TA, UK
}

\begin{abstract}
Alteration of the polyunsaturated fatty acid (PUFA) composition of milk by dietary supplementation of cows may be beneficial to human health. However, dietary PUFAs may influence synthesis of both prostaglandins and steroid hormones. This study examined the effects of dietary PUFAs on reproductive parameters in lactating cows. Cows were fed an isoenergetic control ration $(n=8)$ or a diet supplemented with LinPreme $(n=7)$ or SoyPreme $(n=8)$. These proprietary feeds are derived from linseed or soybeans and contain high concentrations of linolenic acid (LNA, n-3) or linoleic acid (LA, n-6) protected PUFA, respectively. Both PUFA-supplemented diets reduced plasma progesterone, particularly in the early luteal phase, and increased the number of medium-sized $(5-10 \mathrm{~mm}$ in diameter) follicles. The diameter of the first dominant follicle, insulin-like growth factor I (IGF-I) concentrations
\end{abstract}

at oestrus and cholesterol concentrations were all higher in cows fed a diet supplemented with LA (n-6) than in cows that did not receive this supplement. In cows fed a diet supplemented with LNA (n-3), there was an increase in oestradiol during the follicular phase. Diet had no effect on non-esterified fatty acid or insulin concentrations, or on the duration of the oestrous cycle. The plasma concentration of 13,14,dihydro-15 keto PGF $_{2 \alpha}$ after administration of 50 iu oxytocin was unaffected by diet on day 15 and day 16 of the oestrous cycle, but showed a greater response on day 17 in the LA (n-6) supplemented group. Therefore, the PUFA content of the diet can influence both ovarian and uterine function in cows. However, further studies using larger numbers of cows are required to test whether fertility is also affected by such diets.

\section{Introduction}

The report of the Committee on Medical Aspects of Food Policy (Cardiovascular Review Group, Department of Health, 1991) recommended that UK consumers should reduce the proportion of saturated fats and increase the $\mathrm{n}-3: \mathrm{n}-6$ polyunsaturated fatty acid (PUFA) ratio. Epidemiological evidence indicates that this change in diet would lead to a reduced risk of cardiovascular disease. Milk and milk products contribute up to $30 \%$ of the total human fat intake and currently only $4 \%$ of milk fatty acids are unsaturated (Mansbridge and Blake, 1997). The proportion of unsaturated fatty acids in milk can be altered by the inclusion of vegetable or fish oil in the diets of cattle (Wrenn et al., 1976; Schingoethe et al., 1996; Ashes et al., 1997; Demeyer and Doreau, 1999). These oils include various amounts of the two families of essential PUFAs, which are derived from linoleic acid (LA, 18:2, n-6) and $\alpha$-linolenic acid (LNA, 18:3, n-3). LA predominates in most plant oils such as soybean and sunflower oil, whereas LNA predominates in green leaf forages including grass and is also

*Correspondence

Email: dcwathes@rvc.ac.uk present in linseed oil. LA can be converted to the longer chain gamma linolenic (18:3, n-6) and arachidonic acid $(20: 4, n-6)$ by a process of elongation and desaturation, whereas extension of LNA can produce eicosapentaenoic acid (20:5, n-3) and docosahexaenoic acid (22:6, n-3) (Sargent, 1997). Dietary unsaturated fatty acids normally undergo extensive biohydrogenation in the rumen and so do not reach the circulation (Demeyer and Doreau, 1999). However, this process can be reduced by various physical and chemical means of protection (Gulati et al., 1997), thus increasing the absorption of unsaturated fatty acids for subsequent incorporation into tissues and milk.

Studies in a variety of species have shown that dietary PUFAs can modulate prostaglandin synthesis and metabolism (for a review, see Abayasekara and Wathes, 1999; Mattos et al., 2000). Eicosanoids, comprising prostaglandins, thromboxanes, leukotrienes and lipoxins, are all synthesized from C20 fatty acids (Smith, 1989). The most biologically active two series prostaglandins are derived from arachidonic acid, but the less active three series prostaglandins can be produced from eicosapentaenoic acid by the action of the same enzymes (Needleman et al., 1979; Lands, 1992). In most cells, arachidonic acid is present in an esterified form in cellular phospholipids and generation of free 
Table 1. Polyunsaturated fatty acid contents of LinPreme and SoyPreme

\begin{tabular}{lcc}
\hline Fatty acid $\left(\mathrm{g}(100 \mathrm{~g})^{-1}\right.$ fat $)$ & LinPreme & SoyPreme \\
\hline C4:0-C15:0 & All $<1$ & All $<1$ \\
C16:0 & 5.6 & 10.6 \\
C18:0 & 1.3 & 3.9 \\
C18:1 & 10.3 & 20.4 \\
C18:2 (n-6) & 7.6 & 53.7 \\
C180:3 (n-3) & 42.6 & 8.4 \\
C18:4 (n-3) & 13.4 & $<1$ \\
\hline
\end{tabular}

arachidonic acid by either phospholipase $\mathrm{A}_{2}$ or phospholipase $C$ is a rate-limiting step in prostaglandin synthesis (Irvine, 1982; Lapetina, 1982). The composition of cellular phospholipids is related to the dietary lipid intake and thus will play an important role in determining both the amount and type of prostaglandins produced. Although LA and LNA can both act as precursors for prostaglandin synthesis, high amounts of precursor can also reduce both arachidonic acid generation and prostaglandin synthesis via inhibition of phospholipase $\mathrm{A}_{2}$ and cyclo-oxygenase (Thatcher et al., 1995). Arachidonic acid has also been implicated in the acute regulation of steroid synthesis. Trophic hormoneinduced steroid synthesis requires increased expression of steroidogenic acute regulatory protein (StAR), which mediates transfer of cholesterol from the cytosol to the inner mitochondrial membrane (Stocco and Clark, 1996). Arachidonic acid increases the expression of StAR (Wang and Stocco, 1999).

Previous studies on cattle have shown a number of influences of dietary fat supplementation on reproductive function (for a review, see Staples et al., 1998). Fats are often included in cattle diets to increase the energy supplied, although these fats are generally either saturated or unprotected, in which case the majority of the unsaturated fat present will be saturated by microbial action in the rumen before absorption. Effects on fertility (for example, see Burke et al., 1997), ovarian follicular development (for example, see Thomas et al., 1997) and steroidogenesis (for example, see Oldick et al., 1997) have all been reported. The mechanism of action is not clear, although it has been suggested that improved energy status (Hightshoe et al., 1991; Sklan et al., 1994), increased cholesterol availability (Wehrman et al., 1991) and increased serum insulin concentrations (Lammoglia et al., 1997) all enhance ovarian activity.

Dairy cow fertility is already poor: first service conception rates in most herds are below $50 \%$. Furthermore, there has been a steady downward trend in conception rates in some countries over the past 30 years coupled with increasing milk yields (Lamming et al., 1998). As cows are managed more intensively, there has been a decreased dependence on grass as forage and a subsequent increase in the $n-6: n-3$ ratio (Pike and Barlow, 2000). It is therefore important to understand how changing the composition of dairy cow diets to benefit human health and to increase milk production may affect cattle fertility. Furthermore, studies of human populations have indicated that the dietary PUFA intake may alter aspects of human reproduction, including the duration of the menstrual cycle (Reichman et al., 1992) and gestation (Olsen et al., 1992).

The present study was conducted to assess and compare the effects of diets supplemented with plant-derived $n-6$ PUFA (predominantly in the form of LA) or n-3 PUFA (predominantly LNA) on reproduction in lactating dairy cows. Ovarian function was monitored by steroid hormone analysis and ultrasonography, and uterine activity was assessed by measuring the 13,14 , dihydryo-15 keto PGF $_{2 \alpha}$ (PGFM) produced in response to administration of oxytocin. Metabolic hormones (insulin and insulin-like growth factor I (IGF-I)), cholesterol and non-esterified fatty acid (NEFA) concentrations were monitored to investigate whether dietary PUFAs influence reproductive performance via alterations in energy balance.

\section{Materials and Methods}

\section{Animals and diets}

Twenty-two first lactation Friesian/Holstein cows in early lactation were assigned randomly to one of three treatment groups: (i) control ( $n=8)$, (ii) high LNA $(n-3)(n=7)$ or (iii) high LA $(n-6)(n=7)$. The two treatment diets contained either: (ii) an additional $240 \mathrm{~g}$ n-3 PUFA (from LinPreme, Borregaard UK Ltd, Warrington) day ${ }^{-1}$ or (iii) $270 \mathrm{~g} \mathrm{n}-6$ PUFA (from SoyPreme, Borregaard UK Ltd) day ${ }^{-1}$. These PUFAs are non-enzymatically browned full fat linseed or soyabean products, respectively (Abel-Caines et al., 1998). During manufacture, steam is applied to a mixture of xylose solution and cracked soyabeans (or linseed), resulting in the Maillard reaction. This reaction reduces the degradability of the protein in the soyabean and results in the 'protection' of the oils, which are encapsulated by the protein bodies from microbial action in the rumen. The abomasal $\mathrm{pH}$ subsequently allows the protein to be digested, thus releasing the oils for digestion and absorption. It has been estimated that this process provides approximately $50 \%$ protection (Abel Caines et al., 1998). The PUFA contents of LinPreme and SoyPreme and details of the dietary formulations are provided (Tables 1 and 2, respectively). Each diet was formulated to be isoenergetic and isonitrogenous, and provided a metabolizable energy intake of $210 \mathrm{MJ} \mathrm{day}^{-1}$, but the diets differed in their n-6:n-3 PUFA ratios.

The three diets were all mixed from the same batches of ingredients. The diets were offered twice each day as a total mixed ration ad libitum and were introduced gradually over 1 week, reaching the complete diet on day 4 of the trial. Cows were housed throughout the trial with water and mineral licks freely available, and were milked twice each day and observed for oestrous behaviour at least twice each day. The animal experiments were performed under the Animal (Scientific Procedures) Act 1986. 
Table 2. Constituents and composition of the diets fed to cows during the trial

\begin{tabular}{|c|c|c|c|}
\hline Diet & Control & LNA $(n-3)$ & $\mathrm{LA}(\mathrm{n}-6)$ \\
\hline \multicolumn{4}{|l|}{ Constituents } \\
\hline Grass silage $\left(\mathrm{kg}\right.$ day $\left.^{-1}\right)$ & 40.8 & 40.8 & 40.8 \\
\hline Wheat $\left(\mathrm{kg} \mathrm{day}^{-1}\right)$ & 4.0 & 3.0 & 3.0 \\
\hline Sugar beet pulp $\left(\mathrm{kg} \mathrm{day}^{-1}\right)$ & 3.0 & 3.0 & 3.0 \\
\hline Rapeseed meal (kg day $\left.{ }^{-1}\right)$ & 2.4 & 1.3 & 0.5 \\
\hline Soya $48\left(\mathrm{~kg} \mathrm{day}^{-1}\right)$ & 0.75 & 1.0 & - \\
\hline LinPreme $\left(\right.$ kg day $\left.^{-1}\right)$ & - & 1.3 & - \\
\hline SoyPreme $\left(\mathrm{kg} \mathrm{day}^{-1}\right)$ & - & - & 2.8 \\
\hline Dairy minerals $\left(\mathrm{kg} \mathrm{day}^{-1}\right)$ & 0.15 & 0.15 & 0.15 \\
\hline \multicolumn{4}{|l|}{ Composition } \\
\hline Dry matter $\left(k\right.$ day $\left.{ }^{-1}\right)$ & 18.5 & 17.9 & 17.8 \\
\hline Metabolizable energy (MJ day $\left.{ }^{-1}\right)$ & 213 & 207 & 208 \\
\hline MJ kg-1 dry matter & 11.5 & 11.6 & 11.7 \\
\hline Protein in dry matter $(\%)$ & 18.0 & 17.4 & 17.3 \\
\hline $\operatorname{ERDP}\left(\mathrm{g} \mathrm{day}^{-1}\right)$ & 2022 & 1844 & 1852 \\
\hline DUP $\left(\right.$ g day $\left.^{-1}\right)$ & 777 & 758 & 740 \\
\hline $\operatorname{NDF}(\%)$ & 39 & 40 & 40 \\
\hline Oil in dry matter (\%) & 2.7 & 5.0 & 5.0 \\
\hline n-3 PUFA (g day-1) & 198.3 & 439.9 & 234.6 \\
\hline n-6 PUFA (g day $\left.{ }^{-1}\right)$ & 117.3 & 159.0 & 388.9 \\
\hline Ratio n-6:n-3 & 0.59 & 0.36 & 1.66 \\
\hline
\end{tabular}

DUP: digestable undegraded protein; ERDP: effective rumen degradeable protein; LA: linoleic acid; LNA: linolenic acid; NDF: neutral detergent fibre; PUFA: polyunsaturated fatty acid.

\section{Experimental design}

The ovarian activity of each cow was monitored three times a week by a milk progesterone radioimmunoassay (Bulman and Lamming, 1978) throughout the trial. On day 1 of the trial, the cows were treated with a progesterone releasing intravaginal device (PRID; Sanofi Animal Health, Watford) for 10 days to synchronize oestrous cycles. PRID insertion occurred on day $36 \pm 3$, day $37 \pm 3$ and day $38 \pm 3$ after calving in the three treatment groups. Prostaglandin $\mathrm{F}_{2 \alpha}$ analogue, Cloprostenol (500 $\mu \mathrm{g}$ in $2 \mathrm{ml}$, i.m.; Schering-Plough Ltd, Welwyn Garden City) was administered at PRID removal. The cows then went through four treatment cycles, designated as cycles 1-4 (Fig. 1). Blood samples $(10 \mathrm{ml})$ were collected each day throughout the trial from the jugular or ventral coccygeal vein into a heparinized vacutainer (NVS, Stoke-on Trent) or via a jugular catheter (see below) for progesterone radioimmunoassay. Oestradiol was also measured each day during the first two cycles and samples were collected at weekly intervals for analysis of NEFAs, cholesterol and insulin. All blood samples were collected on to ice, centrifuged at $1600 \mathrm{~g}$ for $10 \mathrm{~min}$ at $4^{\circ} \mathrm{C}$ and the plasma stored at $-20^{\circ} \mathrm{C}$.

Starting from the oestrus immediately after PRID removal (termed E1), the ovaries were scanned on alternate days until the subsequent ovulation (E2) by transrectal ultrasonography using an Aloka SSD-500 ultrasound scanner with a 7.5 MHz linear array transducer (BCF Technology Ltd, Livingstone). Each follicle that measured $>5 \mathrm{~mm}$ in diameter was recorded and the presence of corpora lutea was also noted. At the end of cycle 1 (starting from approximately day 17 after E1), scanning frequency was increased to twice a day at 09:00 $\mathrm{h}$ and 17:00 $\mathrm{h}$ until the next ovulation had occurred. At the same time that scanning frequency increased, a jugular vein catheter was inserted $(1.5 \mathrm{~mm}$ by $30 \mathrm{~cm}$ Steriflex; Vygon (UK) Ltd, Cirencester) under mild sedation $(0.5 \mathrm{ml}, 2 \%(\mathrm{v} / \mathrm{v})$ Rompun, i.v.; 23.32 $\mathrm{mg}$ Xylazine $\mathrm{ml}^{-1}$; Bayer plc, Bury St Edmunds) and local anaesthesia (1 ml Lignocaine, s.c. (30 $\mathrm{mg} \mathrm{ml}^{-1}$; Vetoquinol, Bicester). The catheter was kept patent with heparinsaline solution (5000 units heparin $\mathrm{I}^{-1}$; NVS). Blood samples were subsequently collected every $4 \mathrm{~h}$ until ovulation for measurement of LH. Between luteolysis and ovulation, oestradiol sample collection was increased to twice a day and additional samples collected twice a day were obtained for measurement of IGF-I.

During cycle 2, oxytocin was administered on days 15, 16 and 17 after oestrus E2. Blood samples were collected from the i.v. catheter every $15 \mathrm{~min}$ for $1 \mathrm{~h}$ before and $3 \mathrm{~h}$ after i.v. administration of 50 iu oxytocin (Intervet UK Ltd, Cambridge) for subsequent measurement of PGFM by radioimmunoassay.

Cows were re-synchronized during cycle 3 by injection of Cloprostenol ( $500 \mu \mathrm{g}$ in $2 \mathrm{ml} \mathrm{i.m}$.) in the mid-luteal phase (days 7-14). At the induced oestrus, the cows were artificially inseminated (AI) and 12-18 days later were killed at the local abattoir and the reproductive tracts were collected. The uterine tracts were flushed with $30 \mathrm{ml}$ sterile 


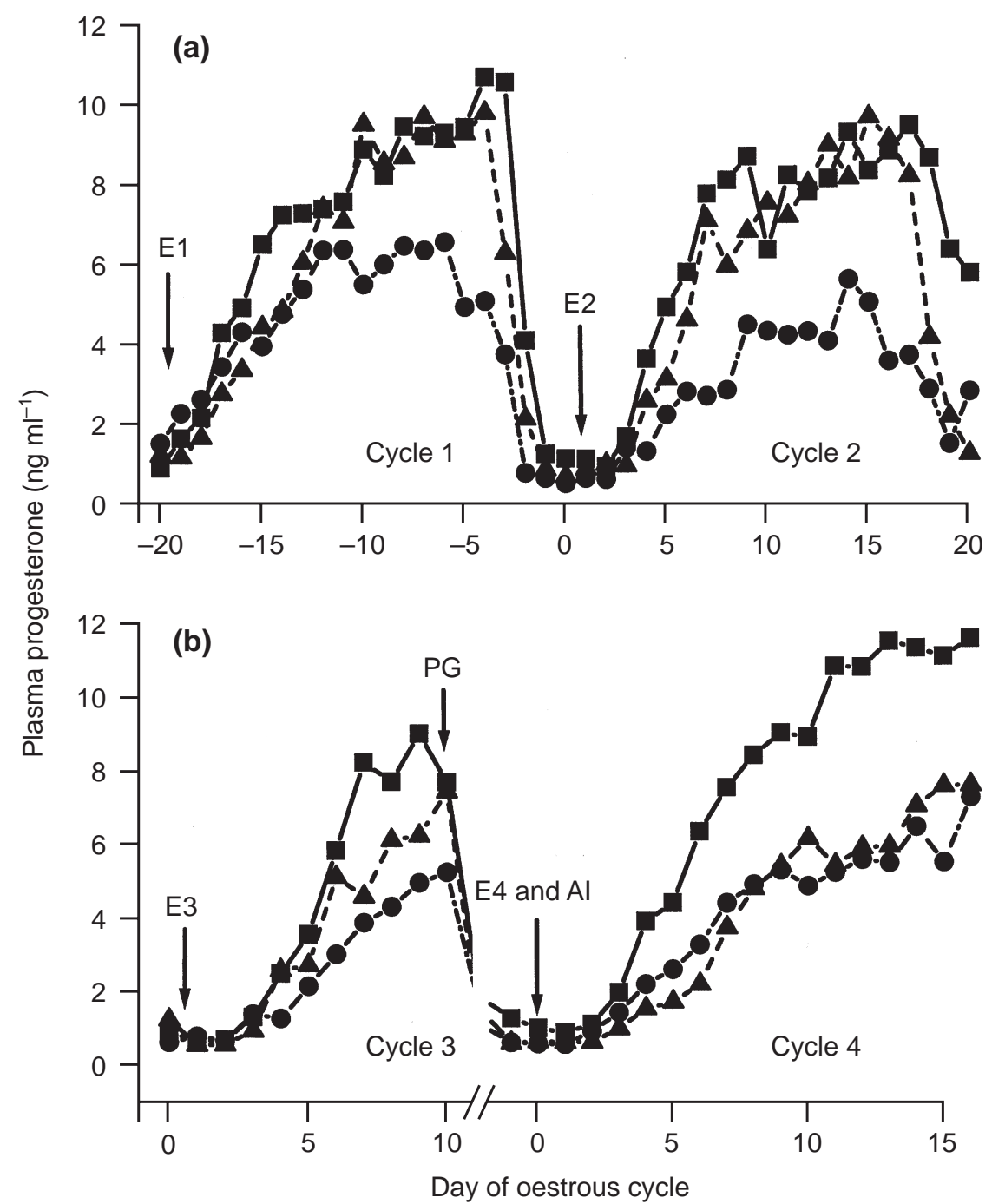

Fig. 1. The effect of dietary polyunsaturated fatty acids (PUFAs) on plasma progesterone concentrations. Progesterone was measured each day in cows maintained on three different diets: (i) control (ם), (ii) high linolenic acid (LNA, n-3) ( ) or (iii) high linoleic acid (LA, n-6) ( $\mathbf{\Delta})$ PUFA. There were seven cows per group. Four oestrous cycles were monitored that are designated as cycles $1-4$. Oestrous periods are labelled E1-E4; E1 occurred after the removal of the progesterone releasing intravaginal device (PRID). Cows were re-synchronized by a single injection of Cloprostenol (PG) during cycle 3 and were artificially inseminated (AI) at E4. The lines show the estimated means. The pooled SES (ng ml-1) were: control: 0.24; LNA (n-3): 0.14; and LA (n-6): 0.22. ANOVA detected a highly significant effect of diet in both the early luteal (days $4-8, P<0.004$ ) and the mid-luteal phase (days $9-15, P<0.02$ ). There was no diet $\times$ oestrous cycle interaction.

saline $(0.9 \%(\mathrm{w} / \mathrm{v}) \mathrm{NaCl})$ per uterine horn to locate the presence of any embryos. Milk samples $(20 \mathrm{ml}$ a.m. and p.m. samples combined) were collected at the end of the trial, frozen and stored for subsequent PUFA analysis.

\section{Plasma hormone and metabolite measurements}

Progesterone. Progesterone was measured in plasma samples after diethyl ether extraction (Wathes et al., 1986).
The antiserum was a gift from M. J. Sauer, Veterinary Laboratories Agency (Addleston). The detection limit was $0.16 \mathrm{ng} \mathrm{ml}^{-1}$ and the inter- and intra-assay coefficients of variation were 10.3 and $6.6 \%$, respectively.

Oestradiol. Oestradiol measurements were made as described by Lane and Wathes (1998). The detection limit was $0.2 \mathrm{pg} \mathrm{ml}^{-1}$ and the inter- and intra-assay coefficients of variation were 11.1 and $6.3 \%$, respectively. 
LH. LH measurements were made using a method based on that described by Wathes et al. (1986). The detection limit was $0.2 \mathrm{ng} \mathrm{ml}^{-1}$ and the intra-assay coefficient of variation was $15.6 \%$. All samples were measured in the same assay.

IGF-I. IGF-I in plasma was analysed after ethanolacetone-acetic acid extraction according to the method of Enright et al. (1989) using rhIGF-I (Bachem (UK) Ltd, Saffron Walden) as standard, iodinated rhIGF-I (iodogen method) as tracer and antibody raised against rhIGF-I (Biogenesis Ltd, Poole). The detection limit was $8.6 \mathrm{ng} \mathrm{ml}^{-1}$ and the interand intra-assay coefficients of variation were 13.5 and $7.6 \%$, respectively.

NEFAs. NEFAs were measured using the Wako NEFA C test kit (Wako Chemicals $\mathrm{GmbH}$, Neuss). The inter- and intra-assay coefficients of variation were 5.2 and $2.3 \%$, respectively.

Cholesterol. Total cholesterol in plasma was determined by an enzymatic colorimetric method using a Sigma Diagnostic cholesterol kit (catalogue number 352-50; Sigma, Poole). The inter- and intra-assay coefficients of variation were 3.5 and $2.6 \%$, respectively.

Insulin. Plasma insulin was measured by ELISA (DRG Diagnostics, Immunodiagnostic Systems Ltd, Tyne and Wear). The detection limit was $0.22 \mathrm{ng} \mathrm{ml}^{-1}$ and the interand intra-assay coefficients of variation were 10.5 and $9.2 \%$, respectively.

PGFM. PGFM was measured in $100 \mu \mathrm{l}$ samples of whole plasma. Standards of PGFM were from Sigma. These standards were spiked with $100 \mu \mathrm{l}$ PGFM-free charcoalstripped cow plasma. The antiserum was a gift from H. Kindahl (Uppsala) and was used at a 1:8000 dilution. The tracer was $\left.{ }^{3} \mathrm{H}\right]$ PGFM (7.07 TBq mmol I-1; Amersham International plc, Amersham) used at 10000 c.p.m. $100 \mu \mathrm{l}^{-1}$. After overnight incubation at $4^{\circ} \mathrm{C}$, separation was achieved by the addition of $200 \mu \mathrm{l}$ dextran-charcoal suspension and centrifugation at $1600 \mathrm{~g}$ for $10 \mathrm{~min}$ at $4^{\circ} \mathrm{C}$. The supernatant was mixed with scintillant $(4 \mathrm{ml}$ Ultima gold; Packard Bioscience B.V., Groningen) and counted for 2 min in a scintillation counter (2500TR liquid scintillation analyser; Packard). The detection limit was $0.01 \mathrm{ng} \mathrm{ml}^{-1}$. The inter- and intra-assay coefficients of variation were 14.3 and $7.6 \%$, respectively.

\section{Milk fatty acid analysis}

The fatty acid composition of the milk samples collected at the end of the trial was determined by ADAS Laboratories (Wolverhampton). In brief, the fat fraction was extracted using diethyl ether. The isolated fat was then trans-esterified using methanolic sodium methoxide to form fatty acid methyl esters (FAME). The FAME profile was determined by capillary gas liquid chromatography. The composition was identified using a certified reference milkfat, a standard solution and equivalent chain lengths. The components were quantified using a standard solution. The mass fraction of an individual fatty acid (as free acid) was expressed as $g$ per $100 \mathrm{~g}$ of the total fatty acids (as free acids).

\section{Statistical analysis}

Results are quoted as the mean \pm SEM unless otherwise stated. Hormonal data were analysed by a general linear model ANOVA program using a repeated measures design (SPSS version 9, Chicago, IL) unless otherwise stated. This design tested for dietary treatment effects and time, and the time $\times$ treatment interaction. If significance was established, multiple comparisons were subsequently performed using Fisher's LSD test. The oestradiol data during different parts of the oestrous cycle were analysed by univariate ANOVA with the data transformed to area under the curve (AUC) of oestradiol concentration against time (days) using the trapezoid method. The duration of the oestrous cycle, the number and diameter of follicles, and the peak oestradiol and peak IGF-I concentrations were analysed by univariate ANOVA. The PGFM data were log-transformed to achieve homogeneity of variance. The basal PGFM production, the concentrations after oxytocin administration and the percentage increase in PGFM over basal production were analysed by split plot ANOVA, with time as the within subjects factor and diet as the between subjects factor. The effect of diet on the peak PGFM value and the AUC were compared using a non-parametric Friedman test. Milk fatty acid data were analysed by multivariate ANOVA. If significance was observed, subsequent comparisons between groups were by LSD. A $P$ value of $<0.05$ was taken to indicate statistical significance.

\section{Results}

\section{Plasma progesterone}

Data were centred on the observed oestrous periods designated E1, E2, E3 and E4 (see Fig. 1), and were analysed including the results from each cow for each of the four cycles (Fig. 2). There was a highly significant effect of diet in both the early luteal (days $4-8, P<0.004$ ) and the midluteal phase (days 9-15, $P<0.02$ ). Although treatment effects appeared to increase with time (Fig. 1), there was no diet $\times$ oestrous cycle interaction. Multiple comparisons showed that progesterone values in the early luteal phase were similar between the LNA (n-3) and LA (n-6) diets, but both were significantly lower than in the control cows (LNA (n-3), $P<0.001$; LA (n-6), $P<0.003$, Fig. 2). In the midluteal phase, progesterone was still significantly lower in cows fed a diet supplemented with LNA (n-3) in comparison with control cows $(P<0.006)$, but there was no difference in progesterone between control cows and cows fed a diet supplemented with LA $(\mathrm{n}-6)(P=0.40)$. 


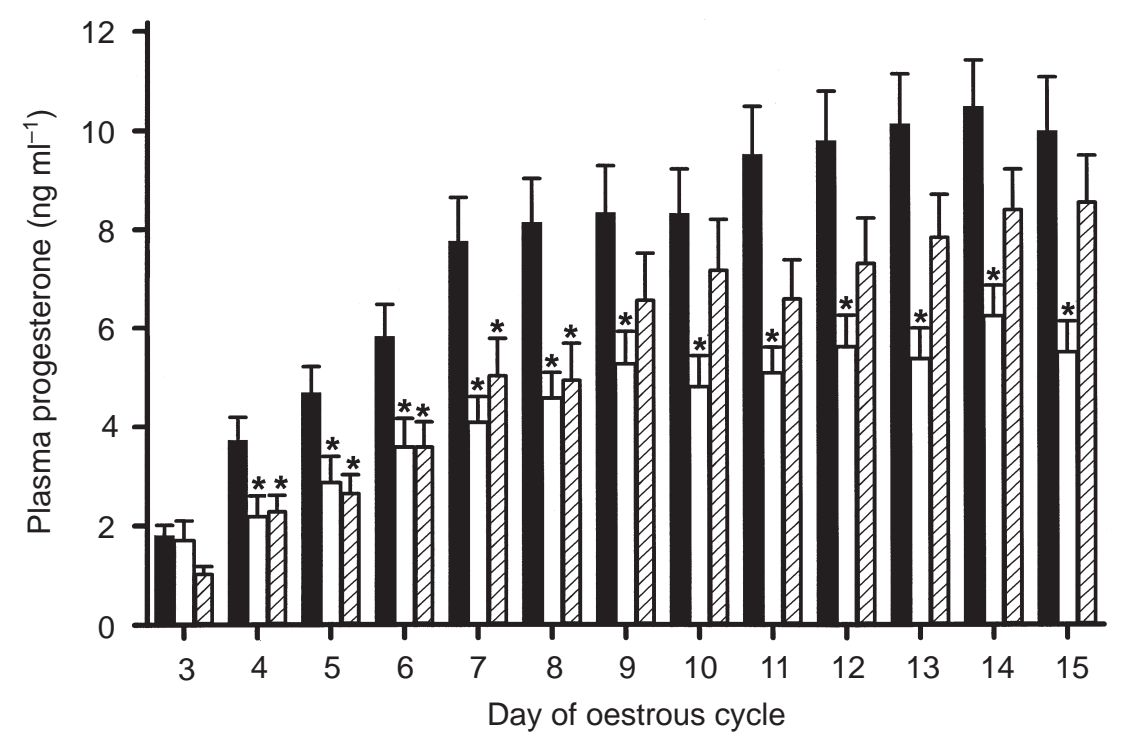

Fig. 2. The effect of dietary polyunsaturated fatty acids (PUFAs) on plasma progesterone concentrations. Values are mean \pm SEM values for each cow from four combined oestrous cycles (E1-E4). Significant differences between the control ( $\square$ ) and PUFA fed (LNA (n-3) ( $\square)$; LA (n-6) ( $\square)$ ) cows are indicated with an asterisk: early luteal phase (days 3-8) control compared with linolenic acid (LNA, n-3), $P<0.001$, and control compared with linoleic acid (LA, n-6), $P<0.003$; mid-luteal phase (days 9-15) control compared with LNA (n-3), $P<0.006$.

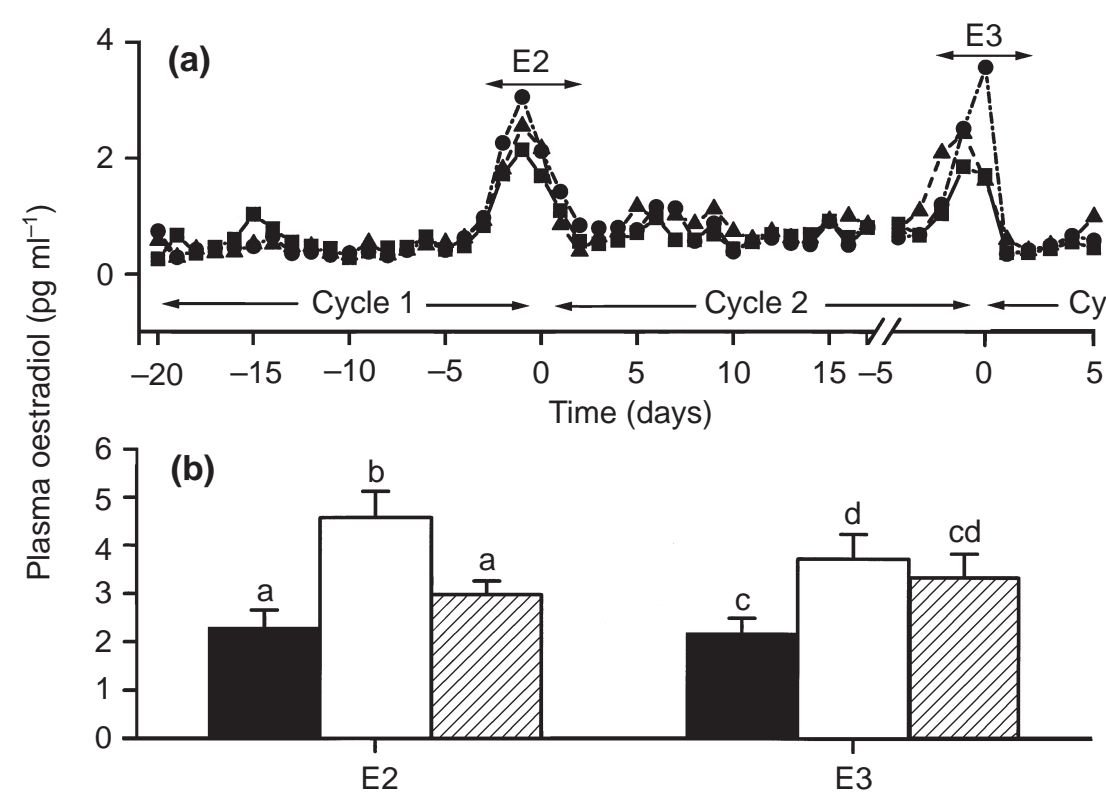

Fig. 3. The effect of dietary polyunsaturated fatty acids (PUFAs) on plasma oestradiol concentrations. (a) Oestradiol concentrations were measured each day in cows maintained on three different diets: (i) control (ם), (ii) high linolenic acid (LNA) (n-3)

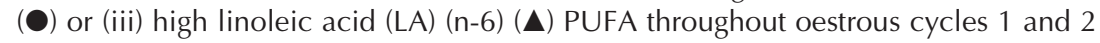
(E1 and E2; $n=7$ per group). Values are the estimated means: the pooled SES (pg ml-1) were: control: 0.04; LNA (n-3): 0.05; LA (n-6): 0.05. The area under the curve for the oestradiol concentrations was significantly higher $(P<0.04)$ in the LNA $(n-3)$ than the control group during each of the oestrous periods (day -3 to day 2 for E2 and E3, indicated by arrows), but not at other stages of the oestrous cycle. (b) The mean \pm SEM maximum oestradiol value recorded during E2 and E3. Values were significantly greater in the LNA (n-3) $(\square)$ cows $(b>a, d>c, P<0.001)$ than the controls $(\square)$, with intermediate values in the LA (n-6) ( $\square)$ group. 


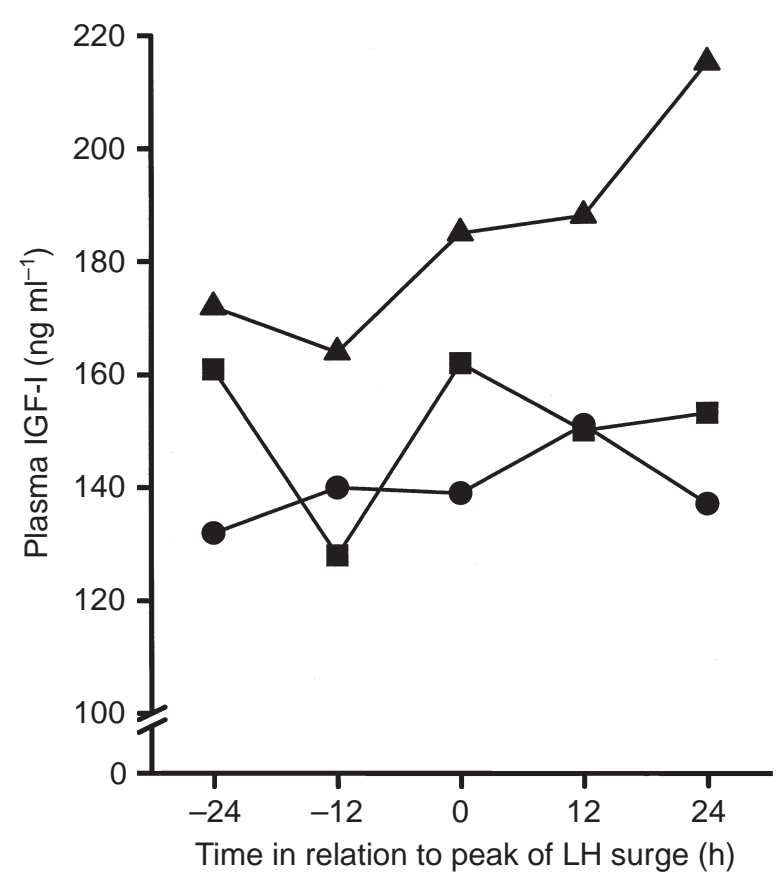

Fig. 4. The effect of dietary polyunsaturated fatty acids (PUFAs) on mean plasma insulin-like growth factor I (IGF-I) concentrations. IGF-I concentrations were measured twice each day in cows maintained on three different diets: (i) control (ם), (ii) high linolenic acid $($ LNA) (n-3) () or (iii) high linoleic acid (LA) (n-6) ( $\mathbf{\Delta})$ PUFA near E2 and were centred on the peak of the LH surge. Values are the estimated marginal means. The pooled SES $\left(\mathrm{ng} \mathrm{ml}^{-1}\right)$ were: control: 11.5; LNA (n-3): 10.5; and LA (n-6): 10.6. There was no significant effect of time for any group, but values were significantly higher in the LA $(n-6)$ group than in the control $(P<0.02)$ and LNA $(n-3)$ groups $(P<0.003)$.

\section{Plasma oestradiol}

Daily oestradiol samples were obtained throughout cycles 1 and 2 until the start of cycle 3 (Fig. 3a) and twice each day from day -3 to day 3 near E2. Data were centred on E2 and E3. Comparisons between treatments were initially made for the whole data set, which showed no difference as a result of diet. Data were then analysed as the $A \cup C$ for the oestradiol values during the preovulatory surge (from day -3 to day 2 for E2 and E3) and during the first follicular wave (from day -19 to day -11 in cycle 1 and day 4 to day 9 in cycle 2). The AUC oestradiol concentrations were significantly different between dietary groups during the preovulatory surge $(P<0.001)$, with multiple comparisons showing that LNA ( $n-3)$ was greater than the control, but there were no significant differences between the groups during the first follicular wave. Finally, the peak oestradiol concentrations recorded during E2 and E3 were compared (Fig. 3b). Concentrations were higher in cows fed a diet supplemented with LNA $(\mathrm{n}-3)$ than in the control cows $(P<0.001)$, with intermediate values in cows fed a diet supplemented with LA (n-6).
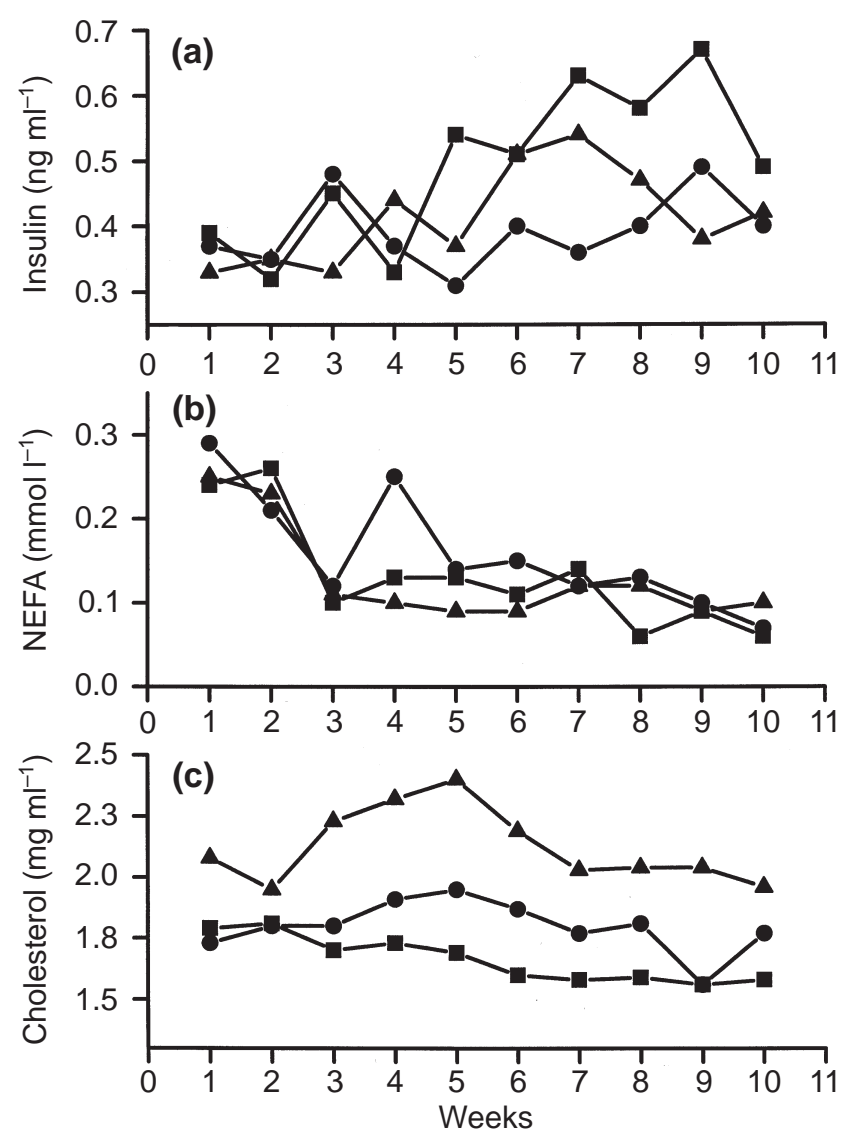

Fig. 5. The effect of dietary polyunsaturated fatty acids (PUFAs) on plasma concentrations of (a) insulin, (b) non-esterified fatty acids (NEFAs) and (c) cholesterol. The concentrations were measured each week in cows maintained on three different diets: (i) control $(\square)$, (ii) high linolenic acid (LNA) (n-3) () or (iii) high linoleic acid (LA) (n-6) ( $\mathbf{\Delta}$ ) PUFA. Values are the estimated means for five to eight cows at each time point. The pooled SES were: insulin (ng $\mathrm{ml}^{-1}$ ): control: 0.044; LNA (n-3): 0.014; LA (n-6): 0.021; NEFA (mmol $\left.\mathrm{l}^{-1}\right)$ : control: 0.026 ; LNA (n-3): 0.026; LA (n-6): 0.028; cholesterol (mg ml-1): control: 0.11; LNA (n-3): 0.12; LA (n-6): 0.12 . For insulin, there was no significant effect of week or diet. For NEFAs, week was significant $(P<0.001)$ but diet was not. For cholesterol, there were significant effects of both week $(P<0.01)$ and diet $(P<0.03)$. The LA $(n-6)$ fed cows had higher concentrations of cholesterol than control cows, with intermediate values in the LNA ( $n-3)$ group.

\section{Metabolic hormones and metabolites}

IGF-I concentrations were measured twice a day near oestrus (E2) and were centred on the time of the LH surge. There was no significant change over time from $24 \mathrm{~h}$ before until $24 \mathrm{~h}$ after the start of the LH surge. Overall, values of IGF-I were significantly higher in cows fed a diet supplemented with LA (n-6) in comparison with control cows $(P<0.02)$ and cows fed a diet supplemented with LNA (n-3) $(P<0.003) \quad$ (Fig. 4). Insulin concentrations were measured each week and were not affected by diet (Fig. 5a). NEFA concentrations decreased between week 2 and week 
Table 3. Effect of diet on follicular parameters in cows fed with polyunsaturated fatty acids

\begin{tabular}{lccc}
\hline Parameter & Control & LNA (n-3) & LA (n-6) \\
\hline Number of cows & 6 & 6 & 6 \\
Number of follicles (5-10 mm in diameter) on day 5 & $1.6 \pm 0.2^{\mathrm{a}}$ & $1.4 \pm 0.3^{\mathrm{a}}$ & $2.3 \pm 0.3^{\mathrm{b}}$ \\
Number of follicles (5-10 mm in diameter) on day 15 & $1.8 \pm 0.3^{\mathrm{a}}$ & $3.4 \pm 0.2^{\mathrm{b}}$ & $3.5 \pm 0.3^{\mathrm{b}}$ \\
Maximum diameter of first dominant follicle (mm) & $13.3 \pm 1.7^{\mathrm{a}}$ & $15.6 \pm 0.7^{\mathrm{ab}}$ & $16.9 \pm 0.7^{\mathrm{b}}$ \\
Maximum diameter of preovulatory follicle (mm) & $17.0 \pm 0.3$ & $18.3 \pm 0.2$ & $17.9 \pm 0.4$ \\
\hline
\end{tabular}

Within rows ${ }^{b}>a(P<0.05)$.

LA: linoleic acid; LNA: linolenic acid.

5 of the trial (approximately week 7 of lactation) in all cows and then remained constant. There was no significant difference in this pattern attributable to diet (Fig. 5b). Cholesterol values remained unchanged during the experimental period in the control cows and in cows fed a diet supplemented with LNA (n-3), and there was no difference between these two diets. In cows fed a diet supplemented with LA (n-6), cholesterol concentrations were increased by week 3 of the trial (week effect, $P<0.01$ ) and then remained higher throughout the trial (overall effect diet control compared with LA (n-6), $P<0.03$, Fig. 5c).

\section{Number and diameter of follicles}

There was a significant effect of diet $(P<0.004)$ on the number of medium-sized follicles (5-10 mm range) present per cow in the first and second follicular waves after the synchronized oestrus (E1). The number of follicles was increased at both time points in cows on the LA (n-6) supplemented diet and on day 15 in cows on the LNA (n-3) supplemented diet in comparison with control cows (Table 2). The maximum diameter of the first dominant follicle measured during cycle 1 and of the preovulatory follicle at E2 was also compared between dietary treatments. The size of the first dominant follicle was significantly greater in cows fed a diet supplemented with LA (n-6) compared with that of the control cows, and intermediate values were noted in cows fed a diet supplemented with LNA (n-3). A similar, although not significant, trend towards an increased diameter was observed in the preovulatory follicles in both the cows fed a diet supplemented with LNA (n-3) or LA (n-6) (Table 3).

\section{Interval from LH surge to ovulation}

The time of the $\mathrm{LH}$ surge was considered as the highest $\mathrm{LH}$ value measured from the $4 \mathrm{~h}$ samples (data not shown). The time of ovulation was estimated as mid-way between the time at which a large dominant follicle was present, and the following scan in which the follicle had disappeared, indicating that ovulation had occurred. The intervals (h) from the LH surge to ovulation for the three treatment groups were as follows: control: mean $22.6 \pm 0.60$, range 21-24; LNA (n-3): mean $23.8 \pm 0.91$, range 22-28; LA (n-6): mean 28.6 \pm 4.57 , range 18-44. In addition, one control cow and one cow fed a diet supplemented with LA (n-6) did not ovulate during the follicular phase, but developed follicular cysts. These data indicate that the interval from the LH surge to ovulation was more variable in the LA (n-6) fed cows, as the variances were not homogeneous between this and the other two groups $(P<0.05)$.

\section{Oestrous cycle duration and fertility}

The duration of oestrous cycles 1 and 2 was measured for each cow as the interval between consecutive oestrous periods (E1-E2-E3). Data were obtained from seven cows per group for two oestrous cycles each. The duration (days) of the oestrous cycles were as follows: control: $21.5 \pm 0.45$; LNA (n-3): $21.7 \pm 0.53$; and LA (n-6): $20.6 \pm 0.30$. One cow fed a control diet had a prolonged luteal phase (34 days) and was omitted from the calculation. One cow fed the LA (n-6) diet developed a follicular cyst at the end of cycle 1, so data from cycle 2 were omitted for this animal. The trend towards a slightly shorter cycle for cows fed the LA (n-6) supplemented diet was not significant $(P=0.25)$.

Pregnancy data were obtained from 18 of the 22 cows. Two animals in each of the control and LA supplemented groups were omitted for the following reasons: two cows were not observed to be in oestrus and so were not inseminated; one cow was inseminated at the wrong time (on the basis of her milk progesterone profile) and one cow was found to have a blocked oviduct post mortem. Excluding these animals, the overall combined pregnancy rate for the three groups was $44 \%$, as determined by the presence of an embryo 12-18 days after Al. The numbers of cows pregnant in individual dietary groups were as follows: control, two of six cows, LNA (n-3), four of seven cows, LA (n-6), two of five cows.

\section{Effect of oxytocin administration on PGFM response}

Cows (five to six per diet) received 50 iu oxytocin i.v. on days 15,16 and 17 of cycle 2. Data were analysed on the basis of the basal, peak and total PGFM concentrations (measured as AUC following oxytocin, Fig. 6) and as the percentage increase in PGFM above baseline after oxytocin administration (Fig. 7). On day 15, there was only a small increase in the PGFM concentration after oxytocin administration, and diet had no effect on the basal, peak, total or percentage increase in PGFM concentrations. The overall response to oxytocin was greater on day 16 , but again there 


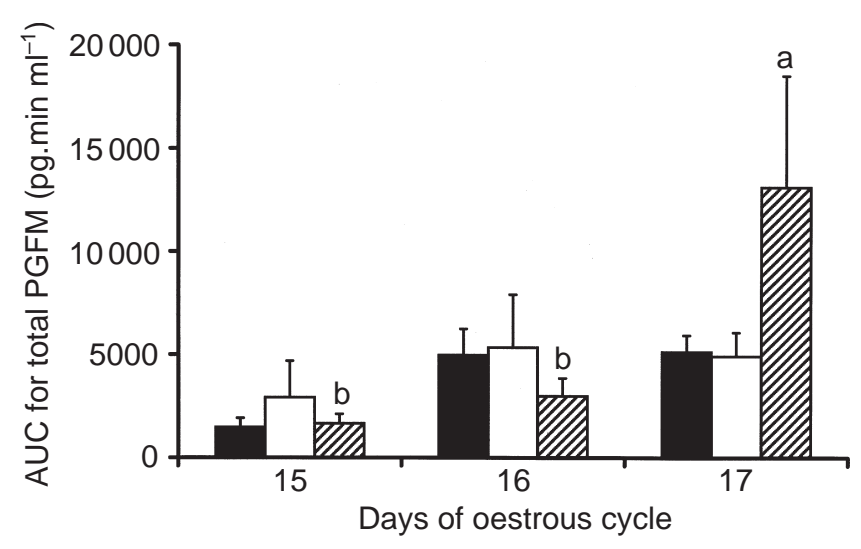

Fig. 6. The effect of dietary polyunsaturated fatty acids (PUFAs) on the 13,14 , dihydryo-15 keto PGF $_{2 \alpha}$ (PGFM) response to the administration of oxytocin. The cows were maintained on three different diets: (i) control $(n=5)(\boldsymbol{\square})$, high linolenic acid (LNA) $(n-3)(n=5)$ $(\square)$ or high linoleic acid (LA) (n-6) ( $(n=6)$. On days 15, 16 and 17 of cycle 2 (see Fig. 1) they were challenged with 50 iu oxytocin and blood samples were collected every 15 min from $1 \mathrm{~h}$ before until $3 \mathrm{~h}$ after oxytocin administration. Values are presented as the mean \pm SEM area under the curve (AUC) for PGFM measured in pg. $\operatorname{min~} \mathrm{ml}^{-1}$ in the $2 \mathrm{~h}$ after the administration of oxytocin. The response in the LA ( $n-6)$ fed cows increased between day 16 and day $17(b>a, P<0.05)$. For the control and LNA ( $n-3)$ groups the smaller increase occurred earlier, between day 15 and day 16 . In these cows there was an overall effect of time $(P<0.05)$ but no 2 days were significantly different.

was no significant effect of diet, although the AUC was lowest in the LA (n-6) supplemented group. On day 17, one cow in the LNA (n-3) supplemented group had a high basal PGFM concentration before oxytocin administration, indicating that it might be experiencing an endogenous pulse of PGFM and, therefore, this animal was omitted from the analysis on this day. Although the control and LNA (n-3) supplemented groups showed a similar magnitude of response on day 16 and day 17 , the amount of PGFM released on day 17 was significantly increased in the LA (n-6) cows $(P<0.05$, Fig. 6). Values were therefore higher in LA ( $n-6)$ cows compared with the control and LNA (n-3) groups, particularly at 45-75 min after oxytocin administration $(P<0.05$, Fig. 7c).

The steroid profiles on days $15-17$ of cycle 2 were examined to determine whether these were related to the differences in PGFM. Plasma progesterone was lower in the LNA (n-3) group compared with the control and LA (n-6) groups $(P<0.001$, data not shown). There were no significant differences in oestradiol. There were also no differences in progesterone concentrations between days, showing that the luteolytic decrease in progesterone had not yet been initiated on day 17 .

\section{Milk fatty acid composition}

Both experimental diets altered the milk PUFA profile (Table 4). Feeding either LNA (n-3) or LA (n-6) reduced the

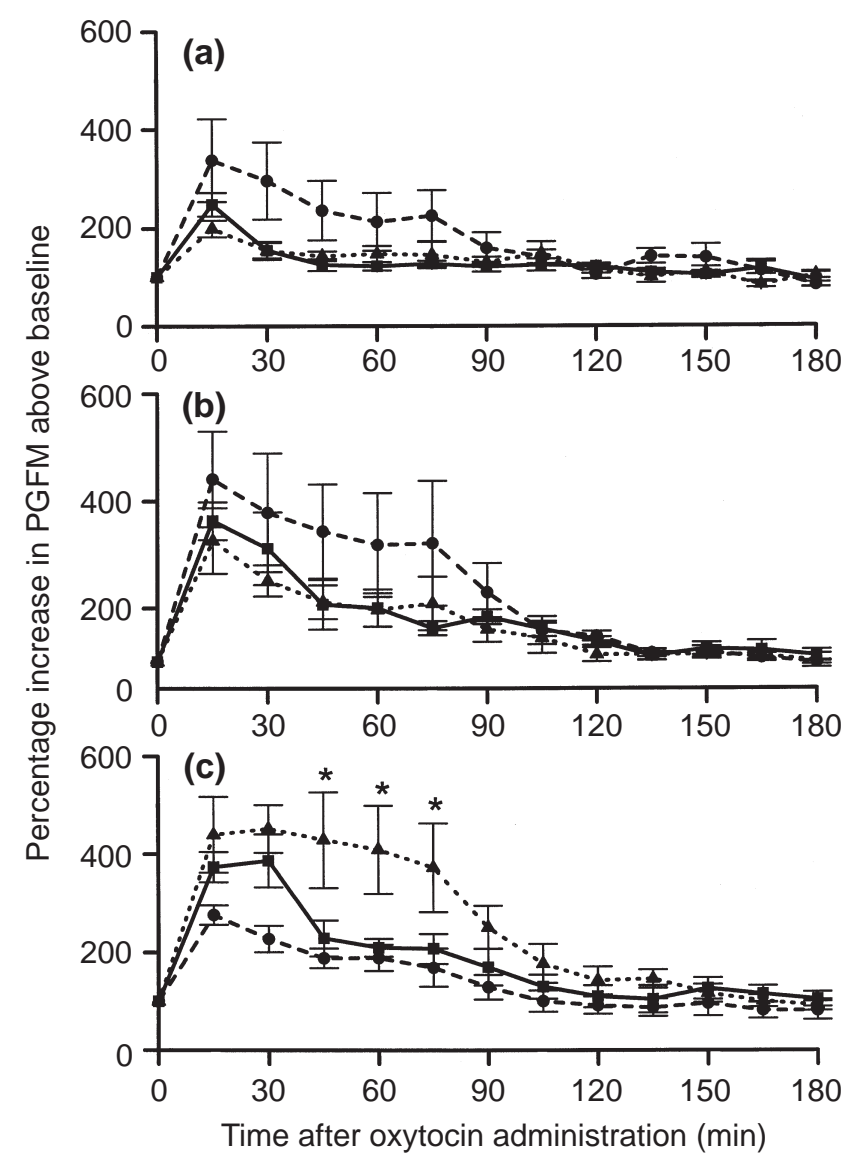

Fig. 7. The effect of dietary polyunsaturated fatty acids (PUFAs) on the 13,14 , dihydryo-15 keto PGF $_{2 \alpha}$ (PGFM) response to the administration of oxytocin. The cows were maintained on three different diets: $(\square)$ control $(n=5)$, ( $)$ high LNA $(n-3)(n=5)$ or $(\mathbf{\Delta})$ high LA $(n-6)(n=6)$. On (a) day 15, (b) day 16 and (c) day 17 of cycle 2 (see Fig. 1), cows received 50 iu oxytocin and blood samples were collected every $15 \mathrm{~min}$ from $1 \mathrm{~h}$ before until $3 \mathrm{~h}$ after oxytocin administration. Values are presented as the mean \pm SEM percentage increase above baseline (calculated from the four prechallenge samples). The diet had no effect on day 15 and day 16; however, on day 17 values were significantly $(* P<0.04)$ increased in LA (n-6) fed cows in comparison with the control cows.

proportion of short chain fatty acids (C4 to C14) and C16:0 saturated fatty acids in milk. LNA concentrations (C18:3) were increased to a similar extent by both PUFA diets. The LA (n-6) diet also caused a large increase in linoleic acid (C18:2), whereas the proportion of arachidonic acid (C20:4 n-6) was decreased by LNA (n-3). The proportions of C18:0, C18:1 and conjugated linoleic acid (C18:2) increased in both PUFA supplemented groups. None of the diets altered the amount of longer chain n-3 PUFAs (C22:5 and C22:6).

\section{Discussion}

The present study has confirmed previous findings that dietary PUFA intake can alter many aspects of reproductive 
Table 4. Fatty acid composition of milk from cows fed the control diet or diets supplemented with linolenic acid (LNA) (n-3) or linoleic acid (LA) (n-6) polyunsaturated fatty acids

\begin{tabular}{lccccc}
\hline $\begin{array}{l}\text { Fatty acid }\left(\mathrm{g}(100 \mathrm{~g})^{-1} \text { fat }\right) \\
\text { (number of cows) }\end{array}$ & $\begin{array}{c}\text { Control } \\
(n=7)\end{array}$ & $\begin{array}{c}\text { LNA }(\mathrm{n}-3) \\
(n=7)\end{array}$ & $\begin{array}{c}\text { LA }(\mathrm{n}-6) \\
(n=6)\end{array}$ & Pooled SEM & $P^{*}$ \\
\hline C4:0-C14:0 (SCFA) & $28.7^{\mathrm{a}}$ & $24.8^{\mathrm{b}}$ & $23.4^{\mathrm{b}}$ & 0.43 & 0.000 \\
C16:0 & $29.0^{\mathrm{a}}$ & $23.4^{\mathrm{b}}$ & $24.3^{\mathrm{b}}$ & 0.34 & 0.000 \\
C16:1 & $1.2^{\mathrm{a}}$ & 1.1 & 1.1 & 0.05 & 0.380 \\
C18:0 & $8.8^{\mathrm{b}}$ & $11.5^{\mathrm{a}}$ & $11.5^{\mathrm{a}}$ & 0.33 & 0.004 \\
Trans $18: 1$ & $1.7^{\mathrm{b}}$ & $2.7^{\mathrm{a}}$ & $2.8^{\mathrm{a}}$ & 0.09 & 0.000 \\
Cis 18:1 & $18.0^{\mathrm{b}}$ & $22.4^{\mathrm{a}}$ & $20.6^{\mathrm{a}}$ & 0.41 & 0.002 \\
C18:2 & $1.6^{\mathrm{b}}$ & $1.6^{\mathrm{b}}$ & $5.4^{\mathrm{a}}$ & 0.08 & 0.000 \\
C18:3 & $0.38^{\mathrm{b}}$ & $0.87^{\mathrm{a}}$ & $0.91^{\mathrm{a}}$ & 0.02 & 0.000 \\
C18:2 cong & $0.65^{\mathrm{b}}$ & $1.2^{\mathrm{a}}$ & $1.2^{\mathrm{a}}$ & 0.04 & 0.000 \\
C20:1 & $0.78^{\mathrm{b}}$ & 0.76 & 0.77 & 0.03 & 0.950 \\
C20:4 n-6 & $0.21^{\mathrm{a}}$ & $0.15^{\mathrm{b}}$ & $0.23^{\mathrm{a}}$ & 0.007 & 0.000 \\
C22:5 n-3 & 0.17 & 0.18 & 0.15 & 0.006 & 0.140 \\
C22:6 n-3 & 0.17 & 0.18 & 0.15 & 0.006 & 0.140 \\
Other & $2.1^{\mathrm{b}}$ & $3.6^{\mathrm{a}}$ & $2.3^{\mathrm{b}}$ & 0.14 & 0.000 \\
\hline
\end{tabular}

SCFA: short chain fatty acids.

${ }^{*}$ Within rows, values with different superscripts were significantly different $\left({ }^{a}>b, P<0.05\right)$.

function and has extended these findings by comparing the effects of feeding protected plant-derived PUFAs from two different families. Plasma progesterone concentrations were reduced, particularly in the early luteal phase, in cows fed a diet supplemented with either LNA (n-3) or LA (n-6) PUFAs. These results are consistent with the study of Hinckley et al. (1996), in which the addition of longer chain PUFAs to dispersed bovine luteal cells decreased progesterone secretion. The mechanism of this process is unknown, although four possibilities should be considered. Firstly, the PUFAs may alter luteal prostaglandin synthesis directly. For example, $\mathrm{PGF}_{2 \alpha}$ in the late luteal phase is luteolytic, whereas $\mathrm{PGE}_{2}$ and 6-keto-PGF $1 \alpha$ are luteotrophic in the early luteal phase (Milvae et al., 1996). A high concentration of LA in the corpus luteum in the early luteal phase could therefore decrease production of luteotrophic prostaglandins. Secondly, there is also growing evidence for a role of arachidonic acid in steroidogenesis. Arachidonic acid can regulate luteal expression of StAR protein and thus may influence LH-stimulated progesterone production, as transfer of cholesterol to the inner mitochondrial membrane is a rate-limiting step (Wang et al., 1999). Thirdly, increased plasma cholesterol concentrations could stimulate progesterone production, although plasma cholesterol is not thought to be rate-limiting to ovarian steroidogenesis (Carroll et al., 1992). Finally, ovulation may be delayed in the PUFA fed cows, leading to delayed luteal development.

None of these explanations are entirely supported by the data from the present study, as the effects of both PUFA diets on progesterone output were fairly similar, but concentrations of the various possible mediators measured in milk or plasma differed between the two PUFA diets. The LA (n-6) supplemented diet increased milk LA and plasma cholesterol, whereas the LNA (n-3) supplemented diet decreased milk arachidonic acid. It is possible either that these measures do not give a true reflection of local concentrations within the ovary or that different inhibitory mechanisms were operative in the two PUFA groups. Whatever the mechanism, lower concentrations of progesterone in the early luteal phase could potentially cause a reduction in fertility, as Mann et al. (1999) reported that cows with lower concentrations of progesterone at this time had significantly smaller embryos on day 16 after insemination. These results using plant-derived protected PUFAs are in contrast with the results of the majority of studies in cattle using saturated fat supplementation in which plasma progesterone is generally increased, often accompanied by raised cholesterol concentrations (for a review, see Staples et al., 1998).

Plasma oestradiol concentrations were increased above control amounts by LNA (n-3) treatment, with intermediate values in the LA (n-6) group. Lammoglia et al. (1997) also found increased oestradiol concentrations throughout the first, but not the second, oestrous cycle after additional fat supplementation using rice bran (which is high in LA) in Brahman cows. The mechanism behind the altered oestradiol synthesis is again unclear. Lower progesterone coupled with the higher oestradiol might indicate alterations in the expression of the steroidogenic enzymes. Insulin and IGF-I can both increase follicular steroidogenesis (Webb et al., 1992; Spicer and Echternkamp, 1995; Wathes et al., 1995). However, in the present study, both cholesterol and IGF-I were increased in cows fed a diet supplemented with LA ( $\mathrm{n}$ 6), but not with LNA (n-3), whereas oestradiol values were highest in the latter group and overall, there was no correlation between peak oestradiol and plasma IGF-I. Furthermore, insulin was not altered by the diet. Data from the present study also showed that there was no increase in circulating IGF-I in the $48 \mathrm{~h}$ period about the time of 
oestrus. This finding is consistent with previous work in cattle (Gong et al., 1993), but differs from the situation in ewes in which circulating concentrations of IGF-I increase at this time, and reach a peak $12 \mathrm{~h}$ after the start of the $\mathrm{LH}$ surge (Spicer and Zavy, 1992; Wathes et al., 1994). The IGF-I concentrations measured in the present study are consistent with other studies in first lactation cows, in which IGF-I concentrations post partum are significantly higher than in older cows (Wathes et al., 2001).

The number and diameter of follicles were also increased in the PUFA fed cows. The effect on follicle size was more pronounced for the first wave dominant follicle than for the preovulatory follicle, possibly because there was little variation in the size at which follicles ovulated, as they were all between $16 \mathrm{~mm}$ and $19 \mathrm{~mm}$ in diameter. This finding is consistent with other reports in which various types of fat supplementation consistently increased both the number and size of ovarian follicles (for example, see Hightshoe et al., 1991; Oldick et al., 1997; Thomas et al., 1997; De Fries et al., 1998). This effect is independent of the increased energy as it is still present in isocalorific diets (Lucy et al., 1991). This conclusion is supported by the unchanged NEFA concentrations found with the different diets in the present study. It has been suggested that the enhanced follicular growth shown in previous work with saturated fats is caused by increased insulin concentrations. However, the relationships between insulin concentrations and follicular development are inconsistent, because in some of the above studies insulin concentrations were increased (Lammoglia et al., 1997; Thomas et al., 1997), whereas in other studies (Beam and Butler, 1997; present study), there was no change. IGF-I is another known stimulator of follicular development (Spicer and Echternkamp, 1995). As IGF-I values were increased only on the LA (n-6) diet, which showed the greatest change in follicle size and number, this is a more likely mediator. An alternative interpretation of the data from the present study is that it could relate to alterations in follicular prostaglandin synthesis as discussed above for the corpus luteum. It is also unclear from any of these investigations whether the increase in follicle size was attributable to more follicular cells, an increased volume of follicular fluid, or both. Although insulin and IGF-I are both known to stimulate granulosa cell proliferation (Webb et al., 1992), the factors causing fluid secretion into the antrum have not, to our knowledge, been studied. The relevance of follicular size to fertility is also unknown as the size of the preovulatory follicle, which could relate to subsequent corpus luteum size, was not altered.

The cows on the LA (n-6) diet had a more variable interval from the $\mathrm{LH}$ surge to ovulation. The mechanism causing this is unknown, but may again be related to alterations in ovarian prostaglandin metabolism. PUFAs could also influence the timing of ovulation via alterations in prostaglandin-mediated changes in $\mathrm{LH}-\mathrm{RH}$ release (Ojeda et al., 1979; Kim and Ramirez, 1986). Variations in the interval to ovulation could be detrimental to fertility as it would be more difficult to time insemination accurately in relation to ovulation, and $\mathrm{Al}$ either too early or too late reduces conception rates (Hunter and Greve, 1997).

Possible effects of the diets on uterine prostaglandin synthesis and subsequent metabolism were examined after oxytocin administration. The LNA (n-3) diet did not alter the PGFM response on days 15, 16 or 17 in comparison with the control diets, whereas the LA (n-6) diet was associated with a higher PGFM in response to oxytocin only on day 17. Several other studies have reported inhibitory effects of $n-3$ PUFAs on prostaglandin synthesis. These effects include in vitro experiments on human decidual cells (Arntzen et al., 1998) and dietary experiments which subsequently tested prostaglandin production by pig alveolar macrophages (Fristche and Cassity, 1996), mice peritoneal cells (Broughton et al., 1991) or a bovine endometrial response to an oxytocin challenge (Coelho et al., 1997). These experiments used the longer chain n-3 PUFAs, docosahexaenoic acid and eicosapentaenoic acid, and it is possible that these are more potent inhibitors of prostaglandin synthesis than $\alpha$-linolenic acid (Elattar and Lin, 1989). Alternatively, the ratio of $n-6: n-3$ PUFAs may have varied between the different experiments.

The effects of n-6 PUFAs on prostaglandin synthesis also remain equivocal. In various in vitro test systems, the addition of LA, di-homo- $\gamma$-linolenic acid (DGLA; 20:3, n-6) or arachidonic acid have been reported to either stimulate (Lewis et al., 1981; Arntzen et al., 1998) or inhibit (Kaduce et al., 1982; Elattar and Lin, 1989) prostaglandin synthesis. In a previous in vivo study, cows were infused with yellow grease into the abomasum. This is a type of fat used in animal feeds in the USA and contains 20\% LA (Oldick et al., 1997). This treatment caused a reduction in uterine PGFM release. A similar decrease in endometrial prostaglandin production was found in a study in which women were fed a diet supplemented with gamma linolenic acid (Graham et al., 1994). The results of the present study indicating that LA was stimulatory on day 17 of the oestrous cycle do not support the suggestion of Thatcher et al. (1995) that LA acts as a competitive inhibitor of prostaglandin synthesis in bovine endometrium. Instead, elongation of LA to arachidonic acid may increase precursor availability for prostaglandin synthesis in this group. However, a further complication is that we have previously reported inhibition of prostaglandin synthesis in endometrial explants obtained on day 15 from cows fed SoyPreme (Cheng et al., 2001), consistent with the slightly lower response in vivo on day 15 shown in the present study. It is possible that these variations in response between days are due to differences in either the local concentrations of LA and arachidonic acid or in their rate of turnover as luteolysis is initiated.

In conclusion, the three diets used in these experiments, which differed primarily in their n-3 and n-6 PUFA content and in the $n-6: n-3$ PUFA ratio, produced a variety of alterations in reproductive function. These included reduced progesterone concentrations in the early luteal phase on both PUFA diets and in the mid-luteal phase on the LNA (n-3) diet, increased follicular number on both diets, 
increased preovulatory oestradiol in the LNA (n-3) fed cows, and increased IGF-I and cholesterol and an increase in follicle size in LA (n-6) fed cows. The LA (n-6) diet also altered the pattern of PGFM release preceding luteolysis as the endometrial PGFM response to an oxytocin challenge was increased. Further experimental work is required to elucidate the mechanisms by which these alterations in circulating hormone concentrations are mediated and to determine whether these changes also influence fertility.

The authors would like to thank N. Poyser, M. Sauer and $\mathrm{H}$. Kindahl for their kind gifts of antiserum, R. Mansbridge for the dietary formulations, G. E. Mann for assistance with the LH assay, D. Manners, J. Thompson and B. Goldsmith for care of the animals, $\mathrm{T}$. Leung for help with the in vitro cultures and M. Dawson for assistance with the catheterization. Financial support was provided by the Ministry of Agriculture, Fisheries and Food. P. G. A. Pushpakumara was supported by a Commonwealth Scholarship.

\section{References}

Abayasekara DRE and Wathes DC (1999) Effects of altering dietary fatty acid composition on prostaglandin synthesis and fertility Prostaglandins, Leukotrienes and Essential Fatty Acids 61 275-287

Abel-Caines SF, Grant RJ, Klopfenstein TJ, Winowiski T and Barney N (1998) Influence of nonenzymatically browned soybeans on ruminal fermentation and lactational performance of dairy cows Journal of Dairy Science 81 1036-1045

Arntzen KJ, Brekke O-L, Vatten L and Austgulen R (1998) Reduced production of $\mathrm{PGE}_{2}$ and $\mathrm{PGF}_{2 \alpha}$ from decidual cell cultures supplemented with n-3 polyunsaturated fatty acids Prostaglandins and Other Lipid Mediators 56 183-195

Ashes JR, Gulati SK and Scott TW (1997) Potential to alter the content and composition of milk fat through nutrition Journal of Dairy Science $\mathbf{8 0}$ 2204-2212

Beam SW and Butler WR (1997) Energy balance and ovarian follicle development prior to the first ovulation postpartum in dairy cows receiving three levels of dietary fat Biology of Reproduction 56 133-142

Broughton KS, Whelan J, Harardottir I and Kinsella JE (1991) Effect of increasing the dietary $(\mathrm{n}-3)$ to $(\mathrm{n}-6)$ polyunsaturated fatty acids ratio on murine liver and peritoneal cell fatty acids and eicosanoid formation Journal of Nutrition 121 155-164

Bulman DC and Lamming GE (1978) Milk progesterone levels in relation to conception, repeat breeding and factors influencing acydicity in dairy cows Journal of Dairy Science $\mathbf{8 0} 2204-2212$

Burke JM, Staples CR, Risco CA, De La Sota RL and Thatcher WW (1997) Effect of ruminant grade menhaden fish meal on reproductive and productive performance of lactating dairy cows Journal of Dairy Science 80 3386-3398

Carroll DJ, Grummer RR and Mao FC (1992) Progesterone production by cultured luteal cells in the presence of bovine low and high density lipoprotein purified by heparin affinity chromatography Journal of Animal Science 70 2516-2526

Cheng Z, Robinson RS, Pushpakumara PGA, Mansbridge RJ and Wathes DC (1998) Effect of dietary polyunsaturated fatty acids (PUFAs) on uterine prostaglandin synthesis in the cow Journal of Endocrinology 171 $463-473$

Coelho S, Ambrose JD, Binelli M, Burke J, Staples CR, Thatcher M-J and Thatcher WW (1997) Menhaden fish meal attenuates estradiol- and oxytocin-induced uterine secretion of $\mathrm{PGF}_{2 \alpha}$ in lactating dairy cattle Theriogenology 47143 (Abstract)

De Fries CA, Neuendorff DA and Randel RD (1998) Fat supplementation influences postpartum reproductive performance in Brahman cows Journal of Animal Science 76 864-870

Demeyer D and Doreau M (1999) Targets and procedures for altering ruminant meat and milk lipids Proceedings of the Nutrition Society $\mathbf{5 8}$ 593-607

Department of Health (1991) Report on health and social subjects 46 Nutritional aspects of cardiovascular disease. Report of the Cardiovascular Review Group Committee on Medical Aspects of Food Policy HMSO, London

Elattar TM and Lin HS (1989) Comparison of the inhibitory effect of polyunsaturated fatty acids on prostaglandin synthesis in oral squamous carcinoma cells Prostaglandins, Leukotrienes and Essential Fatty Acids 38 119-125

Enright WJ, Chapin LT, Moseley WM, Zinn SA, Kamdar MB, Krabill LF and Tucker HA (1989) Effects of infusions of various doses of bovine growth hormone-releasing factor on blood hormones and metabolites in lactating Holstein cows Journal of Endocrinology 122 671-679

Fristche KL and Cassity NA (1996) Metabolism of $\left[{ }^{3} \mathrm{H}\right]$ arachidonic acid by n-3 polyunsaturated fatty acids-enriched piglet alveolar macrophages Prostaglandins, Leukotrienes and Essential Fatty Acids 55 315-323

Gong JG, Bramley T and Webb R (1993) The effect of recombinant bovine somatotrophin on ovarian follicular growth and development in heifers Journal of Reproduction and Fertility $97247-254$

Graham J, Franks S and Bonney RC (1994) In vivo and in vitro effects of $\gamma$-linolenic acid and eicosapentaenoic acid on prostaglandin production and arachidonic acid uptake by human endometrium Prostaglandins, Leukotrienes and Essential Fatty Acids 50 321-329

Gulati SK, Scott TW and Ashes JR (1997) In vitro assessment of fat supplements for ruminants Animal Feed Science Technology 64 127-132

Hightshoe RB, Cochran RC, Corah LR, Kiracofe GH, Harmon DL and Perry RC (1991) Effects of calcium soaps of fatty acids on postpartum reproductive function in beef cows Journal of Animal Science 69 4097-5004

Hinckley T, Clark RM, Bushmich SL and Milvae RA (1996) Long chain polyunsaturated fatty acids and bovine luteal cell function Biology of Reproduction 55 445-449

Hunter RHF and Greve T (1997) Could artificial insemination of cattle be more fruitful? Penalties associated with ageing eggs Reproduction in Domestic Animals 32 137-141

Irvine RF (1982) How is the level of free arachidonic acid controlled in mammalian cells? Biochemical Journal 204 3-16

Kaduce TL, Spector AA and Bar RS (1982) Linoleic acid metabolism and prostaglandin production by cultured bovine pulmonary artery endothelial cells Artherosclerosis 2 380-389

Kim K and Ramirez VD (1986) Effects of prostaglandin E2, forskolin and cholera toxin on cAMP production and in vitro $\mathrm{LH}-\mathrm{RH}$ release from the rat hypothalamus Brain Research 386 258-265

Lamming GE, Darwash AO, Wathes DC and Ball PJ (1998) The fertility of dairy cattle in the UK: current status and future research Journal of the Royal Agricultural Society of England 159 82-93

Lammoglia MA, Willard ST, Hallford DM and Randel RD (1997) Effects of dietary fat on follicular development and circulating concentrations of lipids and insulin on follicular development and circulating concentrations of lipids, insulin, progesterone, estradiol 17 $\beta, 13,14$-dihydro-15keto-prostaglandin $F_{2 \alpha}$ and growth hormone in estrous cyclic Brahman cows Journal of Animal Science 75 1591-1600

Lands WEM (1992) Biochemistry and physiology of $\mathrm{n}-3$ fatty acids FASEB Journal 6 2530-2536

Lane AJP and Wathes DC (1998) An electronic nose to detect changes in perineal odors associated with estrus in the cow Journal of Dairy Science $812145-2150$

Lapetina EG (1982) Regulation of arachidonic acid production: role of phospholipases $C$ and $A_{2}$ Trends in Pharmacological Science 4 115-118

Lewis MG, Kaduce TL and Spector AA (1981) Effect of essential polyunsaturated fatty acid modifications on prostaglandin production by MDCK canine kidney cells Prostaglandins 22 747-759

Lucy MC, Staples CR, Michel FM and Thatcher WW (1991) Effect of feeding calcium soaps to early post-partum dairy cows on plasma prostaglandin $\mathrm{F}_{2 \alpha^{\prime}} \mathrm{LH}$ and follicular growth Journal of Dairy Science 74 483-489

Mann GE, Lamming GE, Robinson RS and Wathes DC (1999) The regulation of interferon production and uterine hormone receptor during early pregnancy in the cow Journal of Reproduction and Fertility Supplement $54317-328$ 
Mansbridge RJ and Blake JS (1997) Nutritional factors affecting the fatty acid composition of bovine milk British Journal of Nutrition 78 Supplement $1 \mathrm{~S} 37-47$

Mattos R, Staples CR and Thatcher WW (2000) Effects of dietary fatty acids on reproduction in ruminants Reviews of Reproduction $\mathbf{5} 38-45$

Milvae RA, Hinckley ST and Carlson JC (1996) Luteotropic and luteolytic mechanisms in the bovine corpus luteum Theriogenology $\mathbf{4 5}$ 1327-1349

Needleman P, Raz A, Minkes MS, Ferrendelli JA and Sprecher H (1979) Triene prostaglandins: prostacyclin and thromboxane biosynthesis and unique biological properties Proceedings National Academy of Sciences USA 76 944-948

Ojeda SR, Negro-Vilar A and McCann SM (1979) Release of prostaglandin $E_{2}$ by hypothalamic tissue: evidence of their involvement in catecholamine-induced LH-releasing-hormone release Endocrinology $104617-624$

Oldick BS, Staples CR, Thatcher WW and Gyawu P (1997) Abomasal infusion of glucose and fat: effect on digestion production, and ovarian and uterine function of cows Journal of Dairy Science 80 1315-1328

Olsen SF, Sorensen JD and Secher NJ (1992) Randomised controlled trial of effect of fish-oil supplementation on pregnancy duration Lancet 339 1003-1007

Pike IH and Barlow SM (2000) The fats of life: the role of fish Lipid Technology 12 58-60

Reichman ME, Judd JT, Taylor PR, Nair PP, Jones Y and Campbell WS (1992) Effect of dietary fat on length of the follicular phase of the menstrual cycle in a controlled diet setting Journal of Clinical Endocrinology and Metabolism 74 1171-1175

Sargent JR (1997) Fish oils and human diet British Journal of Nutrition 78 Supplement 1 S5-S13

Schingoethe DJ, Brouk MJ, Lightfield KD and Baer RJ (1996) Lactational responses of dairy cows fed unsaturated fat from extruded soybeans or sunflower seeds Journal of Dairy Science 79 1244-1249

Sklan D, Kaim M, Moallem U and Folman Y (1994) Effect of dietary calcium soaps on milk yield, body weight, reproductive hormones, and fertility in first parity and older cows Journal of Dairy Science 77 1652-1666

Smith WL (1989) The eicosanoids and their biochemical mechanisms of action Biochemical Journal 259 315-324

Spicer LJ and Echternkamp SE (1995) The ovarian insulin and insulin-like growth factor system with emphasis on domestic animals Domestic Animal Endocrinology 12 223-245

Spicer LJ and Zavy MT (1992) Concentrations of insulin-like growth factor-I in serum of sheep with different ovulation rates: changes during the estrous cycle Theriogenology 37 395-405

Staples CR, Burke JM and Thatcher WW (1998) Influence of supplemental fats on reproductive tissues and performance of lactating cows Journal of Dairy Science 81 856-871
Stocco DM and Clarke BJ (1996) Regulation of acute production of steroids in steroidogenic cells Endocrine Reviews 17 221-244

Thatcher WW, Meyer MD and Danet-Desnoyers G (1995) Maternal recognition of pregnancy Journal of Reproduction and Fertility Supplement 49 15-28

Thomas MG, Bao B and Williams GL (1997) Dietary fats varying in their fatty acid composition differentially influence follicular growth in cows fed isoenergetic diets Journal of Animal Science 75 2512-2519

Wang X and Stocco DM (1999) Cyclic AMP and arachidonic acid: a tale of two pathways Molecular and Cellular Endocrinology 158 7-12

Wang X, Walsh LP and Stocco DM (1999) The role of arachidonic acid on LH-stimulated steroidogenesis and steroidogenic acute regulatory protein accumulation in MA-10 mouse Leydig tumor cells Endocrinology 10 7-12

Wathes DC, Guldenaar SEF, Swann RW, Webb R, Porter DG and Pickering BT (1986) A combined radioimmunoassay and immunocytochemical study of ovarian oxytocin production during the periovulatory period in the ewe Journal of Reproduction and Fertility 78 167-183

Wathes DC, Perks CM and Stevenson KR (1994) Insulin-like growth factor-I (IGF-I) synthesis in the ovine reproductive tract: possible interactions between uterus and ovary Proceedings, $26^{\text {th }}$ Annual Conference Australian Society for Reproductive Biology p 54

Wathes DC, Perks CM, Davis AJ and Denning-Kendall PA (1995) Regulation of insulin-like growth factor I and progesterone synthesis by insulin and growth hormone in the ovine ovary Biology of Reproduction 53 882-889

Wathes DC, Taylor VJ and Cheng Z (2001) Metabolic interactions with fertility Cattle Practice 9 291-296

Webb R, Gong JG, Law AS and Rusbridge SM (1992) Control of ovarian function in cattle Journal of Reproduction and Fertility Supplement $\mathbf{4 5}$ 141-156

Wehrman ME, Welsh TH and Williams GL (1991) Diet-induced hyperlipidemia in cattle modifies the intrafollicular cholesterol environment, modulates ovarian follicular dynamics and hastens the onset of postpartum luteal activity Biology of Reproduction 45 514-522

Wrenn TR, Weyant JR, Wood DL, Bitman J, Rawlings RM and Lyon K (1976) Increasing polyunsaturation of milk fats by feeding formaldehyde protected sunflower-soybean supplement Journal of Dairy Science $\mathbf{5 9}$ 627-635

Received 5 October 2001.

First decision 15 November 2001.

Revised manuscript received 27 March 2002.

Accepted 28 March 2002. 